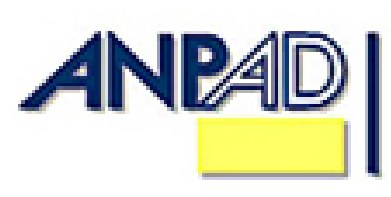

Available online at

http://www.anpad.org.br/bar

\title{
The Transition from Alliance Networks to Multilateral Alliances in the Global Airline Industry
}

\author{
Sergio G. Lazzarini* \\ E-mail address: SergioGL1@isp.edu.br \\ Ibmec São Paulo \\ São Paulo, SP, Brazil
}

\begin{abstract}
This study examines conditions in which alliance networks (informal webs of bilateral entanglements between firms) may or may not evolve into multilateral alliances (broad, formal multiple-firm arrangements). I offer a theory to explain the formation of multilateral alliances based on both the resource profile and the structure of existing interfirm networks, and provide an initial test of that theory in the context of the global airline industry. Using data from 75 global airlines and their alliances, I propose a methodology to retrieve samples of alliance networks and then use regression analysis to assess how the resource profile and the structure of these networks influence their formalization into multilateral alliances. I find that multilateral alliances are more likely to emerge when alliance networks exhibit high resource diversity and network structure characterized by moderate density and high centralization. Apparently, while highly sparse networks reduce actors' awareness of their potential joint collaboration, highly dense or embedded networks substitute for the need for formal controls accompanying multilateral agreements. The effect of centralization suggests that the formation of multilateral alliances tends to be triggered by leading actors directly connected to other network members.
\end{abstract}

Key words: alliance networks; multilateral alliances; constellations; cooperative strategy; airline industry.

Received 02 March 2007; received in revised form 23 January 2008.

Copyright (C) 2008 Brazilian Administration Review. All rights reserved, including rights for translation. Parts of this work may be quoted without prior knowledge on the condition that the source is identified.

*Corresponding author: Sergio G. Lazzarini

Ibmec São Paulo, Rua Quatá, 300, São Paulo/SP, Brazil, 04546-042. 


\section{INTRODUCTION}

A recent trend altering patterns of interfirm interaction has been the formation of alliances among multiple autonomous firms, which collaborate among themselves and compete against other groups of firms for both clients and members (Gomes-Casseres, 1994, 1996). Evidence of the formation of such groups pervades the literature, including industries as diverse as computer and microprocessors (Vanhaverbeke \& Noorderhaven, 2001), telecommunications (Joshi, Kashlak, \& Sherman, 1998), financial services (Domowitz, 1995), automobiles (Nohria \& Garcia-Pont, 1991) and global airlines, which are the focus of this study (Hanlon, 1999; Lazzarini, 2007; Lazzarini \& Joaquim, 2004). Linkages between international airline carriers, for instance, imply that travelers will have several substitute routes to reach a particular destination, serviced by groups of firms exploiting complementary legs. The emergence of associations between multiple firms has led some scholars to propose that the locus of competition has shifted from firms to groups of firms that collaborate with one another (Gomes-Casseres, 1996).

One way of analytically demarcating the membership of a firm in those alternative groups is to observe the structure of bilateral or dyadic associations between firms, such as pair-wise agreements or equity stakes (Nohria \& Garcia-Pont, 1991; Vanhaverbeke \& Noorderhaven, 2001). In this sense, Gomes-Casseres (1996) defines an alliance network as a group of "separate companies linked through collaborative agreements," though "not all the companies in a group have to be linked directly to all the others" (p. 65). For instance, an airline carrier may develop an agreement to offer joint connections with two other international carriers, which may or may not have a direct agreement with each other. Moreover, a firm in a technology-intensive industry may develop an R\&D project with another firm, which may in turn create a marketing agreement with a third party, and so forth. Using Das and Teng's (2002) characterization, alliance networks are simply a "collection of several alliances" among players in a certain industry (p. 446). Multiple-firm collaboration in an alliance network is therefore implicit because there are no formal terms guiding the joint action of firms, even though pair-wise ties may be, to some extent, formalized.

In some circumstances, however, a restricted group of firms decides to formalize their mutual association in a multilateral alliance composed of overarching agreements applicable to all members of the group (Doz \& Hamel, 1998). Instead of a collection of several alliances between firms, a multilateral alliance is a broad multiple-firm alliance. Multilateral alliances often involve formal entities to manage the affairs of the group (such as decision-making committees) and even common investment in brand names and technology platforms. In the airline industry, multilateral alliances are exemplified by global groupings such as the Star Alliance, Oneworld and SkyTeam, in which carriers develop broad agreements to share traffic, pursue joint operations, and develop common marketing programs, thus going beyond webs of agreements negotiated on a largely bilateral basis.

Therefore, this paper attempts to answer the following research question: Why do firms involved in an alliance network decide to formalize their association in a multilateral alliance? In other words, what determines the chosen governance structure of the network as a whole? Even though there is a great deal of studies analyzing governance choices in dyadic alliances (e.g. Gulati, 1995; Pisano, 1989), research into the organization of interfirm networks has been scant. For the most part, the literature has downplayed the role of formal controls and contracts in alliance networks, arguing that extensive interfirm linkages allow for informal mechanisms of governance that promote cooperation (Granovetter, 1985; Uzzi, 1996). Studies analyzing processes of network formalization, on the other hand, have generally treated the formation of multilateral alliances as an evolutionary process in which joint action is institutionalized over time (e.g. Doz, Olk, \& Ring, 2000). Consequently, most research into networks has not described conditions in which multilateral agreements will emerge because scholars have rarely pointed out factors that may or may not trigger the formalization of networks. 
I fill this void by offering hypotheses that are initially tested using data from 75 global airlines and their alliances. The airline industry has seen a surge in alliances between carriers, in part because regulatory barriers prevent access to global resources and markets through the outright acquisition of domestic airport facilities or carriers (Hanlon, 1999). Thus, alliances have become a crucial mechanism for carriers to internalize interfirm externalities in the form of international traffic flows. Initially, carriers sought to create bilateral associations involving either equity stakes or pair-wise alliances such as codesharing (whereby two carriers combine routes as a single composite product to customers) and marketing agreements (joint frequent flyer programs and combined promotion efforts). Observing patterns of bilateral partnering in the industry, analysts have long noted the existence of alliance networks corresponding to groups of bilaterally tied firms servicing a web of routes and competing with carriers offering alternative connections (Whitaker, 1996).

In the mid 1990s, however, carriers began to create formalized groups competing for traffic (Star Alliance, Oneworld, SkyTeam etc.). These groups correspond to multilateral alliances because agreements are applicable to all partners and are broad in nature. For instance, they involve full marketing cooperation with respect to frequent flyer programs and promotion (including investments in a common brand name), in addition to joint access to airport facilities controlled by individual members. They also offer comprehensive codesharing agreements comprising several routes instead of bilateral agreements comprising few routes. Estimates indicate that these multilateral alliances contributed to almost $60 \%$ of global air traffic in 2001, representing 203.3 billion dollars in revenues (Baker, 2001). Therefore, although focusing on the airline industry may prevent the generalization of empirical results to other contexts, it nonetheless provides a rich setting for an empirical examination of how alliance networks may or may not evolve into multilateral alliances.

The paper proceeds as follows. In the next section, I develop testable hypotheses grounding the theory discussion in the context of the airline industry to facilitate understanding and to provide a more direct link to the empirical analysis. I next describe the methods employed to test the hypotheses, and then discuss the results. Concluding remarks follow.

\section{HYPOTHESES}

My theory employs the network as the unit of analysis (Dyer \& Singh, 1998). In particular, I build upon the recent body of knowledge analyzing multiple-firm alliances. Scholars have described the emergence of such groups and discussed the motivation for firms to engage in multiple-firm networks (Dhanaraj \& Parkhe, 2006; Gomes-Casseres, 1994; Lorenzoni \& Ornati, 1988). In a given industry, one can typically observe several multiple-firm alliances competing against each other for both clients and members. Initially, empirical studies attempted to observe such networks in different industries and demarcate the boundaries of groups (e.g. Nohria \& Garcia-Pont, 1991; Vanhaverbeke \& Noorderhaven, 2001). More recent empirical research has attempted to examine the performance implications of membership, i.e., what happens if firms decide to participate in a multiple-firm alliance and how firms may attain different gains depending on their individual characteristics (e.g. Lavie, Lechner, \& Singh, 2007; Lazzarini, 2007; Rowley, Baum, Shipilov, Greve, \& Rao, 2004).

Competing groups of firms pursuing joint action are also referred to as constellations, although scholars have used this term in different ways. Some have characterized constellations as alliance networks (Gomes-Casseres, 1994, 1996), while others have characterized constellations as multilateral alliances (Das \& Teng, 2002). A possible way to reconcile those different views is to consider alliance networks as constellations that are implicitly or informally organized, and multilateral alliances as constellations that are explicitly or formally organized (Lazzarini, 2007). In this sense, I contribute to this literature by proposing a theory describing factors that will affect the governance of multiple-firm alliances. In particular, I analyze how such groups may evolve from informal alliance networks to formal multilateral alliances. I do not intend to discuss the formation of dyadic ties and alliance networks mainly because past research has examined this issue in detail (Gimeno, 2005). Instead, I 
take networks as given and describe factors that might influence the benefits of formalizing interfirm linkages in a multilateral alliance: the profile of resources available in the group and the overall structure of the alliance network. This theory is detailed next.

\section{Profile of Resources in the Network}

At the most fundamental level, the benefits of interfirm cooperation largely depend on the possibility to internalize positive externalities emanating from multiple firms. The possibility of capturing those externalities increases when members hold complementary resources, i.e., when the use of a resource increases when it is jointly used with other resources supplied by partners (Lavie, 2007). This tends to occur when firms have specialized roles and hence contribute to the network with diverse resources that can be combined with one another (Grandori \& Soda, 1995). For instance, an airline carrier can capture traffic-driven externalities emanating from other carriers servicing alternative routes. Since international regulations prevent a carrier from owning foreign infrastructure, that carrier can complement its route network by partnering with firms controlling alternative hubs (and their associated routes), thereby pooling traffic coming from different regions.

The benefits of resource diversity, however, come at a cost. Firms must overcome problems of coordination and cooperation that arise when exploiting diverse resources. The existence of complementarities implies that resources could be recombined in several ways. Uncoordinated decision-making may therefore lock firms into sub-optimal outcomes (Levinthal, 1997). The exploitation of resource complementarities also requires firms to co-specialize their assets (Doz \& Hamel, 1998). Therefore, airline carriers may need to jointly invest in idiosyncratic information technology to support their operations, or engage in promotion activities to support their collective marketing efforts. Lack of cooperation may result if members act opportunistically, for instance by free riding on collective investments (Nault \& Tyagi, 2001). Transaction cost logic also suggests that firms may be reluctant to co-specialize resources if they fear that certain partners will engage in adversarial haggling after investments are consummated (Williamson, 1991).

I submit that the formalization of an interfirm network in a multilateral alliance may help overcome problems of coordination and cooperation in a context of high resource diversity. Consider first the effect of formalization on the ability of firms to coordinate their joint efforts. Whereas in alliance networks firms fundamentally interact on a pair-wise basis (e.g. two carriers establishing codesharing agreements to exploit joint routes), in multilateral alliances such interactions tend to be more comprehensive and general. This process is facilitated by the adoption of common, standardized exchange procedures in multilateral alliances. Standardization creates compatibility across members' production and marketing systems, thereby expanding the possibility to exploit complementarities (Thompson, 1967). Furthermore, the process of creating formal agreements and discussing collective strategies in decision-making committees represents an opportunity for extensive communication and negotiation, which reduces the likelihood that the group will be trapped into inferior outcomes (Farrell \& Saloner, 1985). For instance, in the airline industry both the Star Alliance and the Oneworld group have established management teams involving executives from member carriers (Baker, 2001). These features of multilateral alliances can also promote cooperation. Not only do formal decision-making committees improve interfirm communication, but they also represent a mechanism for mutual monitoring. In addition, by establishing clauses specifying the role and obligations of members, formal agreements can curb partner defection expressed as free riding or opportunistic haggling. As a result, it is likely that formalization will increase firms' confidence in their joint endeavor, thereby increasing their willingness to co-specialize assets (Poppo \& Zenger, 2002).

However, all these formal features (comprehensive contracts, common platforms, decision-making committees etc.) are costly. Formalization may not result in net benefits unless problems of coordination and cooperation are severe. Therefore, the network will more likely be formalized if resource diversity is high. In other words: 
Hypothesis 1. An increase in the diversity of resources available in the alliance network will increase the likelihood that firms will formalize their association in a multilateral alliance.

\section{Structure of the Alliance Network}

The structure of the alliance network should also influence the likelihood that it will be formalized in a multilateral alliance. I examine three features related to network structure: density, extent of ties to outside actors, and network centralization.

Network density. Scholars associated with the so-called social embeddedness perspective have forcefully argued that a dense web of bilateral ties among firms - i.e., when they are extensively connected with one another - will help mitigate problems of coordination and cooperation involved in collective action (Granovetter, 1985; Uzzi, 1996). By enhancing group cohesion, network density tends to facilitate joint action and improve communication, consequently reducing the likelihood of coordination failure (Jones, Hesterly, Fladmoe-Lindquist, \& Borgatti, 1998). Dense networks also promote the emergence of shared norms that enhance cooperation. These arguments could imply, at first glance, that the likelihood of network formalization should be monotonically decreasing in the density of the group: the informal mechanisms brought by a dense web of ties should substitute them for the formal mechanisms (discussed before) associated with multilateral alliances.

I propose instead a more complex relationship. If an alliance network is sparse, then actors may not recognize their potential joint collaboration. Firms may simply form bilateral associations independently of what other network partners are doing. Some degree of density may be necessary to increase firms' awareness of possible network partners, which could be co-opted for a newly formed multilateral alliance. Furthermore, if one or more firms decide to create a multilateral alliance, they can attract other firms to which they are bilaterally tied (Gomes-Casseres, 1994). This will tend to economize on search costs and allow partners to create a comprehensive alliance building upon existing bilateral arrangements. Thus, a movement from sparse networks to moderately dense networks should increase the likelihood of multilateral alliance formation. After density reaches a certain point, then the informal governance mechanisms that accompany dense networks should start substituting for the formal mechanisms associated with multilateral alliances, hence diminishing the need for formalization. Therefore, I propose a curvilinear, inverted-U effect of network density on the likelihood that the network will be formalized:

Hypothesis 2a. Highly dense and highly sparse alliance networks will be less likely to be formalized in a multilateral alliance than networks with moderate density.

Since network density promotes coordination and cooperation, it should also help firms deal with high levels of resource diversity. Therefore, extensive, dense ties increase communication and allow firms to discuss and exploit diverse possibilities of resource combinations. Moreover, a group of airline carriers may be more willing to co-specialize their route infrastructures even in the absence of a formal joint agreement if they perceive that most partners have ties to one another. If one firm acts opportunistically in this case, it should expect the severance of its ties to other members of the network. Therefore, network density should attenuate the effect of resource diversity on the need of formalization, which suggests a negative interaction between density and resource diversity. In other words:

Hypothesis 2b. The positive effect of resource diversity on the likelihood of an alliance network's formalization in a multilateral alliance will be lower when the alliance network is highly dense.

Extent of ties to outside firms. Pursuing joint action with members of an alliance network while maintaining extensive ties to outside actors will likely reduce a firm's commitment to the group (Lavie, 2007). Extensive outside ties denote a promiscuous orientation, whereby firms decide to preserve their flexibility to assess alternative partners (Jones et al., 1998). These firms should be reluctant to join formal multiple-firm alliances because this could curtail their partnering options. Firms with extensive outside ties will also be less focused on any particular group, thereby making it 
difficult for the group to develop joint strategies. Furthermore, an airline carrier establishing bilateral ties to firms belonging to alternative multilateral alliances will be able to partially benefit from the traffic generated by those groups without incurring the costs of creating and maintaining them. Thus, sparseness in outside connections will likely increase firms' mutual orientation to the objectives of the network as a whole, and guarantee that the value generated within the network is largely internalized by its members. As a result, firms will be more willing to invest in the formalization of the network. I therefore propose:

Hypothesis 3. The higher the extent to which firms of an alliance network have ties to other firms outside the network, the lower the likelihood that it will be formalized in a multilateral alliance.

The existence of outside ties will also worsen the problems of coordination and cooperation that arise when members try to exploit diverse resources. This effect is symmetrically opposite to the effect of network density. In this way, extensive outside ties should make a firm less inclined to discuss and develop ways to combine and exploit resources in a particular group. In addition, carriers may become reluctant to co-specialize their route networks if they perceive that partners have several exit options. Therefore, the presence of extensive outside ties should magnify the effect of resource diversity on the need of formalization; diverse resources will require formal structures designed to support coordination and cooperation especially when partners need to combine diverse resources. In other words:

Hypothesis 3b. The positive effect of resource diversity on the likelihood of an alliance network's formalization in a multilateral alliance will be higher when network members have extensive ties to firms outside the alliance network.

Network centralization. Even if the network is not highly dense, it may involve a hub or central firm that "sets up the network, and takes a pro-active attitude in the care of it" (Jarillo, 1988, p. 32). For instance, an airline carrier may develop its own set of direct agreements with other international carriers, planning their joint routes and coordinating the activities of the network as a whole. Instead of a clique, the alliance network in this case would be characterized as a star, whereby a central firm creates alliances with other actors who, in turn, have few ties to one another and to other firms (Grandori \& Soda, 1995; Vanhaverbeke \& Noorderhaven, 2001). A highly centralized network (Wasserman \& Faust, 1994) occurs when a firm has high centrality (i.e., it is tied to many other network members), while other firms have low centrality (i.e., they are sparsely tied to one another). If there is a firm that is outstandingly central in a given network, it may act as a triggering entity that initiates the creation of a multilateral agreement with its partners (Doz et al., 2000) without relying on hierarchical authority (Dhanaraj \& Parkhe, 2006). The process of network formalization is likely to be facilitated when a central firm leads the process and coordinates the achievement of common objectives. In fact, most multilateral alliances in the airline industry were basically initiated by key players in the industry: for instance, the Star Alliance has been led by United Airlines and Lufthansa, while American Airlines and British Airways had a pivotal role in the creation of Oneworld (Baker, 2001). These firms have long established bilateral ties to several carriers that have later become members of formal groups. This argument leads to the final hypothesis:

Hypothesis 4. The higher the centralization of an alliance network, the higher the likelihood that it will be formalized in a multilateral alliance.

\section{DATA AND METHODS}

\section{Data}

The data used in this study include 75 global airlines representing about $80 \%$ of the total world passenger traffic and 54 distinct countries (Table 1), observed from 1997 to 2001. The data come 
mostly from the World Air Transport Statistics compiled by the International Air Transport Association (IATA), which provides information on airlines' operations (traffic, capacities etc.), and the Airline Business magazine, which presents annual surveys of bilateral alliances (codesharing, marketing agreements etc.) and equity stakes between carriers, as well as the composition of multilateral alliances in the industry (Star Alliance, Sky Team, Oneworld etc.).

\section{Assessing Alliance Networks}

A first step in the analysis of alliance networks is to define a way to construct a matrix of bilateral ties. I adopt a simple criterion by considering that there is a linkage between two firms (coded 1) when they have either a bilateral alliance or an ownership relation (i.e., when at least one of the carriers has an equity stake in the other carrier). Otherwise, I consider that there is no linkage (coded 0). Such a matrix is constructed for every year in the sample. Although membership in multilateral alliances is readily observable, alliance networks are more difficult to analyze because their boundaries are inherently subjective. An alliance network could involve the set of partners to which a firm is directly tied; but it could also include indirect connections such as the set of partners of that firm's direct partners.

Instead of adopting a particular method to demarcate alliance networks, one could generically evaluate all possible combinations of firms. This method, however, would be computationally daunting. Since the database includes 75 carriers, the number of alternative combinations of, say, 5 firms would be higher than 17 million. To simplify the analysis, I proceed in an alternative way. Based on the yearly matrix of bilateral ties, I generate an algorithm to randomly draw network samples involving a pre-specified number of firms. For instance, I randomly pick a group of 5 carriers among the 75 carriers in the database. I then compute the density of the network sample, i.e., the total number of observed bilateral ties divided by the total number of ties that could possibly be formed between those firms (Wasserman \& Faust, 1994). It only makes sense to include network samples with some degree of bilateral linkage between firms. Therefore, I only keep random samples where network density is at least .1, and then calculate the variables of interest for those network samples (explained below). Otherwise, I discard the sample and proceed with another random draw of firms. I then repeat this procedure a certain number of times for each year for networks with different sample sizes.

Obviously, it is necessary to define how many network samples will be extracted from the data in each year, and the size of each sample (number of firms). Since the primary objective is to explain the formation of multilateral alliances, it is natural to look for sample sizes that correspond to the size of those observed alliances. In this sense, for each year I assess the number of carriers belonging to multilateral alliances of different sizes. For instance, in early 2000 there were 16 carriers belonging to two 8-firm multilateral alliances (Oneworld and Qualiflyer); 3 carriers belonging to one 3-firm alliance (SkyTeam); and 12 carriers belonging to one 12-firm alliance (Star). Thus, 9.7\% of the firms associated with some multilateral alliance in 2000 were part of a 3-firm alliance; $51.6 \%$ were involved in an 8-firm alliance; and 38.7\% were involved in a 12-firm alliance. Defining a target of 2,000 network samples for the year 2000, I then generate random samples with numbers of firms equal to the sizes of the observed multilateral alliances in a given year, based on the above proportions. Thus, I randomly draw $2,000 \times 0.097=194$ networks with 3 firms, $2,000 \times 0.516=1032$ networks with 8 firms, and $2,000 \times 0.387=714$ networks with 12 firms. When dealing with the previous years, I adopt the same procedure, but adjust the target number of samples according to yearly changes in the participation of firms in multilateral alliances.

\section{Dependent Variable}

Each observation (unit of the analysis) in the constructed database corresponds to a network sample $C_{k}$ with size $s_{k}$, i.e., it is a random sample of $s_{k}$ firms with network density of at least 0.1 . The goal is to observe whether those randomly sampled firms belong to the same multilateral alliance or not in a given year, and then examine factors that might explain their formal association. In this sense, for each 
network sample $C_{k}$, I compute the following metric, referred to as Multilateral ${ }_{k}$, which is used as dependent variable:

Multilateral $_{k}=\frac{\sum_{i \in C_{k}} \sum_{j \in C_{k}} m_{i j}}{s_{k}\left(s_{k}-1\right)}$,

where $m_{i j}$ is equal to 1 if firms $i$ and $j \in C_{k}$ are observed in the same multilateral alliance in a given year, and 0 otherwise. This variable attains a maximum value of 1 if all randomly sampled firms are observed in the same multilateral alliance, and a minimum value of 0 if firms are observed in different multilateral alliances or in no alliance whatsoever. To avoid spurious causal inferences, the dependent variable is observed at year $t+1$ and the independent variables, described below, are observed at year t. Consequently, all independent variables are lagged by construction. Thus, I use data on alliance networks from 1997 to 2000, which are then used to explain membership in multilateral alliances observed from 1998 to 2001.

\section{Explanatory Variables}

Resource diversity. I create two variables measuring the resource diversity of each network sample. The first measure, named Hub diversity, is based on the idea that carriers positioned in distant cities or hubs will be more able to exploit new route combinations to customers than carriers positioned in proximate hubs (see Lazzarini, 2007). Such proximate hubs are more likely to be substitutes than complements. In other words, the average distance between the hubs controlled by carriers will be indicative of the extent to which they are providing the alliance network with diverse resources (e.g., local infrastructure). Therefore, for each network sample $C_{k}$ with size $s_{k}$, I compute the variable Hub diversity $_{\mathrm{k}}$ as follows:

Hub diversity $=\frac{\sum_{i \in C_{k}} \sum_{j \in C_{k}} d_{i j}}{s_{k}\left(s_{k}-1\right)}$

where $d_{i j}$ is the distance (in thousands of kilometers) between the main hubs of firms $i$ and $j \in C_{k}$. The main hub of a carrier is defined as the city which, for that particular carrier, shows the largest number of departing connections as evidenced by the Traffic by Flight Stage database, compiled by the International Civil Aviation Organization (ICAO). In cases where carriers have more than one hub, as well as secondary hubs, the choice of any particular domestic hub should not drastically affect the final metric because the alliances studied here are mostly international. Thus, the hubs of carriers from different countries are much more distant from each other than are the domestic hubs of any single carrier in the database.

The second measure of diversity concerns the heterogeneity of carriers in terms of seat capacity. Small firms may specialize in local or domestic routes, while large firms may specialize in long international connections. To exploit new routes, carriers will have to co-specialize their local infrastructure and competencies in distinct market arenas. Thus, for each network sample $k$ with size $s_{k}$, I compute the variable Capacity diversity $\mathrm{k}_{\mathrm{k}}$, which is the standard deviation of the $s_{k}$ firms' seat capacity, in billions of ASKs (available seat kilometers, a widely used measure of capacity in the industry).

Network density. As explained above, the density of a network sample network $k$, denoted as Density $_{\mathbf{k}}$ is simply the observed number of existing bilateral ties relative to the total possible number of ties between the randomly sampled carriers (Wasserman \& Faust, 1994).

Extent of ties to outside firms. For each network sample $C_{k}$ with size $s_{k}$, I construct the variable Outside ties as follows: 
Outside ties $_{\mathrm{k}}=\frac{\sum_{i \in C_{k}} \sum_{j \notin C_{k}} b_{i j}}{s_{k}\left(N-s_{k}\right)}$,

where $b_{i j}$ is equal to 1 if there is a bilateral tie between firms $i \in C_{k}$ and $j \notin C_{k}$, and 0 otherwise. $N$ is the total number of firms in the grand network; since I am considering 75 carriers in total, $N=75$. Intuitively, while Density $y_{\mathbf{k}}$ is a measure of within-group density, Outside ties $_{\mathbf{k}}$ is a measure of between-group density (Wasserman \& Faust, 1994). It is equal to 0 if no member of the alliance network has ties with non-members, and equal to 1 if all members have ties to all non-members.

Network centralization. The centralization of a network sample $C_{k}$ with size $s_{k}$ can be measured as follows (Wasserman \& Faust, 1994):

Centralizationk $=\frac{\sum_{i \in C_{k}}\left(B_{\max }-B_{i}\right)}{\left(s_{k}-1\right)\left(s_{k}-2\right)}$,

where $B_{i}$ is the total number of bilateral ties between firm $i \in C_{k}$ and other members of the network sample (i.e., it corresponds to $i$ 's degree centrality), and $B_{\max }$ is the maximum degree centrality observed within the network. This variable assumes the maximum value of 1 when the alliance network is a star (i.e., when a firm is bilaterally tied to all other network members, which in turn are not tied to one another), and the minimum value of 0 when the network is either totally dense (all firms are tied to one another) or a circle (Wasserman \& Faust, 1994).

\section{Control Variables}

Multimarket contact. Contact in multiple markets occurs when two or more carriers serve similar routes. In this study, controlling for multimarket contact is important for two reasons. First, as shown by Gimeno and Woo (1996), multimarket contact may be correlated with resource similarity. Since multimarket contact facilitates tacit collusion and hence attenuates the competitive pressure within a network, failure to control for multimarket contact may bias the analysis of the impact of a network's resource profile on the likelihood that the network will be formalized. Second, as proposed by Sakakibara (2002) in the context of R\&D alliances, "contact with other firms in product markets constitutes a network through which the firm can obtain superior information on future consortia" (p. 1937). Therefore, similarly to network density, multimarket contact may be a way in which firms become aware of their strategic interdependence, thus possibly influencing their willingness to form a multilateral alliance. Studies of multimarket contact in the airline industry have considered city-pair routes as the relevant markets or points of contact (Gimeno \& Woo, 1996). Thus, using the Traffic by Flight Stage database, I compute the variable $r_{i j}$ representing the number of international city-pair routes jointly serviced by two carriers $i$ and $j$ belonging to a network sample $C_{k}$ in a given year. The final measure, denoted as Multimarket contact $\mathbf{k}_{\mathbf{k}}$ measures the average number of route contacts between two firms belonging to the network sample.

Average traffic. This variable is included to control for differences in traffic among the network samples. Average traffic is the sum of sampled carriers' total traffic (in billions of revenues passenger kilometers or RPKs, a measure of traffic in the industry), divided by the total number of firms in each network sample.

Cargo diversity. Since most multilateral alliances are devised to exploit passenger traffic, carriers' orientation toward cargo activities might influence their desire to jointly formalize their network. For this reason, I add the control variable Cargo diversity, which is the standard deviation of the ratio of cargo activity (measured in billion revenue tonne kilometers or RTKs) to the number of employees (in thousands), computed for each carrier in the network sample. 
Average Routes. This variable is intended to check for differences in the amount of international routes serviced by the sampled carriers. It corresponds to the average number of international routes (in thousands of routes, according to the Traffic by Flight Stage database) offered by carriers belonging to each network sample.

Sample size. Since network samples have varying numbers of firms, it is important to monitor these differences. Thus, I create a set of dummy variables, denoted as Sample size, representing the number of firms involved in each network sample, according to the size categories given in Table 4.

Year controls. Finally, I create a set of dummy variables representing each year in the observation window, denoted as Year(t), in order to control for temporal effects such as variations in economic and regulatory conditions over time, as well as trends in the pattern of multilateral alliance formation.

\section{Method}

The decision to form a multilateral alliance is likely to involve a two-stage process. A group of firms should first decide whether to join any multilateral alliance, and then which alliance to join. A network of firms will consider formalizing their association in a multilateral alliance if and only if individual firms become interested in joining some formal group. Thus, to test the hypotheses presented before, it makes sense to restrict the analysis to network samples with a reasonable number of firms participating in some (though not necessarily the same) multilateral alliance. In other words, I analyze the likelihood that the sampled firms will become part of the same alliance as most of the firms have decided to join some multilateral alliance.

Within this perspective, I employ the standard two-stage Heckman model (Heckman, 1979). In the first stage, taking all network samples, I run a Probit model where the dependent variable, Participation, is equal to 1 if at least $42.2 \%$ of the firms in the network sample participate in some multilateral alliance, and 0 otherwise. This cutoff value (42.2\%) corresponds to the average proportion of firms in each network sample that are observed in some multilateral alliance, considering all network samples, and is used to dichotomize the dependent variable in the Probit regression. As independent variables, I use all explanatory and control variables described before plus three instrumental variables: the total number of carriers that were observed in some multilateral alliance in the previous year, which captures an institutionalization process whereby carriers' willingness to join any multilateral alliance will be reinforced by the number of firms that have already adhered to those alliances (Gulati \& Gargiulo, 1999; Hannan \& Freeman, 1989); a measure of the carrier’s international orientation, corresponding to the sum of sampled carriers' total traffic coming from international routes (in RPKs), divided by the total number of firms in each network sample; and a measure of the average size (capacity, in ASKs) of the firms within each network sample. Because multilateral alliances are essentially global arrangements, one should expect that carriers more involved with international operations and with larger operational scale are more likely to participate in those formal groups.

In the second stage, taking the subset of network samples where Participation $=1$, I run OLS regressions of Multilateral (the dependent variable) on the explanatory and control variables, plus the inverse Mills ratio resulting from the first-stage Probit regression. The inverse Mills ratio should control for potential biases that might occur given that I am considering only a subset of network samples in the final analysis.

The estimation method employs the Huber-White estimator to compute standard errors. The procedure generates robust estimates that control for potential heteroscedasticity in the data. I note that although the Heckman procedure employed here requires normality of the error terms associated with the outcome variable, in my case this variable (i.e., Multilateral) has clear upper and lower bounds (from 0 to 1). Alternatively, I could have employed the so-called Tobit model, which explicitly accommodates such bounds. To check the robustness of my results, I ran Tobit regressions and observed that the inference about the variables was similar to the Heckman procedure (results not 
reported here, but available upon request). Therefore, I opted to use the Heckman model to test my hypotheses - which, as I discuss next, is justified given that self-selection is apparently flagrant in my context.

\section{RESULTS AND DISCUSSION}

Table 2 presents the results of two-stage Heckman regressions. I only report results from secondstage OLS regressions, whose estimates are used to test the hypotheses presented above (results from the first-stage probit estimation stage are available upon request). One can observe that the inverse Mills ratio is highly significant across all model specifications reported in Table $2(p<.01)$, which indicates that selectivity bias is relevant in my context and hence the use of the Heckman model is warranted.

Model 1 in Table 2 presents baseline results including control variables only. The significant effect of Multimarket contact $(p<.01)$ is particularly interesting. Confirming Sakakibara's (2002) conjecture, firms in an alliance network that encounter more frequently in multiple markets are more likely to formalize their association in a multilateral alliance. Possibly, contacts in multiple markets (routes) increase carriers' awareness of their strategic interdependence, which might influence their propensity to form a broad alliance. This effect is robust across all model specifications. The other control variables do not show consistent effects, except Average routes in models 2 and 3: an increase in the average number of international routes offered by firms in each network sample increases their willingness to engage in the same multilateral alliance ( $p<.01$ for models 2 and 3$)$.

Model 2 adds explanatory variables related to the resource profile and structure of the network samples. These explanatory variables, in conjunction, significantly improve the fit of the regression $(F$ $=19.70, p<.01$ ). Results provide support for Hypothesis 1: the variables measuring resource diversity in the network samples, Hub and Capacity diversity, significantly increase the extent of firms' participation in the same multilateral alliance $(p<.01$ and $p<.05$ respectively). Thus, alliance networks whose firms have hubs distant from one another and heterogeneous capacities are more likely to be formalized. This is consistent with the idea that the organization of networks as multilateral alliances (instead of informal webs of bilateral associations) is a possible way to overcome problems of coordination and cooperation that arise when actors seek to exploit complementary resources.

The same model allows for a test of the hypotheses related to the structure of network samples. Both Density and its square value are highly significant and with the expected signs $(p<.01)$, thus confirming a curvilinear, inverted-U relationship between the density of network samples and the likelihood of their formalization (Hypothesis 2a). Based on the estimated coefficients, membership in the same multilateral alliance is most likely when density is around .203. Apparently, while highly sparse networks reduce actors' awareness of their potential joint collaboration, highly dense or embedded networks substitute for the need for formal structures to accompany multilateral agreements. The insignificance of variable Outside ties, however, refutes Hypothesis 3a: the extent of ties between members of each network sample and outside firms does not account for membership in the same multilateral alliance. Finally, support is found for Hypothesis 4: Centralization shows a significantly positive coefficient $(p<.01)$. Therefore, other things being equal, alliance networks involving one or few central firms are more likely formalized, which is aligned with the conjecture that the formation of multilateral alliances tends to be triggered by leading actors directly connected to other network members.

Model 3 adds interactions between resource profile and network structure, which are used to test Hypotheses $2 \mathrm{~b}$ and $3 \mathrm{~b}$. These interactions, in conjunction, significantly improve the fit of the regression ( $F=2.97, p<.05$ ), and do not qualitatively change the above results. However, only the interactions involving Hub diversity as a measure of resource profile are significant. Confirming 
Hypotheses $2 \mathrm{~b}$ and $3 \mathrm{~b}$ respectively, an increase in network density attenuates the positive effect of hub diversity on the likelihood of network formalization $(p<.01)$, while an increase in the extent of outside ties magnifies that effect $(p<.05)$. Apparently, the social embeddedness brought about by network density helps firms solve the problems of coordination that emerge in a context of diverse resources, and make them more willing to co-specialize those resources even in the absence of formal, general agreements. Interestingly, although Outside ties shows no significant main effect, it interacts positively with Hub diversity. A possible explanation is that the adverse effect of having extensive outside ties is only relevant when potential problems of cooperation and coordination are acute (i.e., when resource diversity is high). In these conditions, a network with several outside ties may be associated with low interfirm interaction and commitment, thus requiring formal mechanisms of communication and control. When cooperation and coordination failure are not likely, outside ties should not severely affect group performance.

\section{CONCLUDING REMARKS}

This study contributes to the literature on interfirm networks by moving beyond the focus on dyadic alliances and examining conditions in which alliance networks (informal webs of bilateral entanglements between firms) may or may not evolve into multilateral alliances (broad, formal multiple-firm arrangements). To the best of my knowledge, this issue was not properly explored by previous studies; existing work tends to focus on the organization of bilateral deals instead of the way in which alliance networks are governed as a whole. I offer a theory to explain the formation of multilateral alliances based on both the resource profile and the structure of interfirm networks, and provide an initial test of that theory in the context of the global airline industry. In this sense, I contribute to the evolving literature on competing multiple-partner alliances (e.g. Lavie et al., 2007; Lazzarini, 2007; Rowley et al., 2004) by focusing on factors that should influence the organization of such groups. The study also informs managers about how govern their portfolio of alliances-in particular, defining the characteristics of alliance networks that should invite formalization through broader, multilateral deals. In a nutshell, the data confirm that alliance networks most likely to be formalized as multilateral alliances exhibit the following characteristics: high resource diversity, moderate density, and high centralization.

The study, however, has important limitations, which open up avenues for future research. First, the airline industry presents many particularities that prevent the results from being generalized for other contexts. Therefore, the international traffic in the industry is heavily regulated, which certainly influences the formation of alliances because firms are generally not free to enter foreign countries through acquisitions. Nonetheless, I believe that this study can serve as a potential guide for future research in other industries. For instance, in the computer and microprocessor industry, firms have not only established networks of bilateral alliances for technology development and licensing, but also formal, multilateral R\&D consortia (Vanhaverbeke \& Noorderhaven, 2001). In addition, in the financial industry, firms have moved beyond bilateral deals to structure formal, multilateral exchange organizations (Domowitz, 1995). It would be interesting to examine whether the theory proposed here-which is general in its essence-holds up in these different industry settings.

Second, the results may be time-specific. Therefore, given that my data cover the period from 2007 to 2001, carriers in my sample were not affected by the September $11^{\text {th }}$ attacks, which greatly affected traffic growth in the airline industry and, arguably, may have influenced their decisions to form and maintain alliances. Although traffic growth resumed in 2004-2005 and airline carriers continued to engage in multilateral alliances, future research could expand the temporal window of the database and see whether the same results hold after 2001. In other words, it will be important to check the temporal generalizability of my results.

A third limitation of this study is that alliance networks are not readily observable entities. One could consider a firm's alliance network as the set of its direct partners; but one could also include in 
that network the set of partners of that firm's direct partners. An alternative way to examine these groups, which is not immune to criticism, is to define criteria to demarcate alliance networks, for example, through cluster analysis (Lazzarini, 2007; Nohria \& Garcia-Pont, 1991; Vanhaverbeke \& Noorderhaven, 2001). Further research into alternative methods to retrieve alliance networks based on the pattern of bilateral partnering between firms is particularly welcome.

Finally, this study essentially takes the structure of alliance networks as exogenous. This is a simplifying assumption to facilitate the generation and test of initial hypotheses on the formation of multilateral alliances based on existing interfirm networks. However, the emergence of multilateral alliances has implications for the formation or dissolution of bilateral associations between firms, which could in turn change the structure of alliance networks. An analysis of this sort would require complex, multi-level theories and data with longer temporal horizons. This massive, yet crucial, effort of theory building and data collection is left for future work.

\section{REFERENCES}

Baker, C. (2001, July). The global groupings: the five contenders in the global alliance race are shown below with their tally of members and associated carriers, as of mid-June this year. Airline Business, p. 42.

Das, T. K., \& Teng, B-S. (2002). Alliance constellations: a social exchange perspective. Academy of Management Review, 27(3), 445-456.

Dhanaraj, C., \& Parkhe, A. (2006). Orchestrating innovation networks. Academy of Management Review, 31(3), 659-669.

Domowitz, I. (1995). Electronic derivatives exchanges: implicit mergers, network externalities, and standardization. The Quarterly Review of Economics and Finance, (35), 163-175.

Doz, Y. L., \& Hamel, G. (1998). Alliance advantage: the art of creating value through partnering. Boston: Harvard Business School Press.

Doz, Y. L., Olk, P. M., \& Ring, P. S. (2000). Formation processes of R\&D consortia: which path to take? Where does it lead? Strategic Management Journal, 21(3), 239-266.

Dyer, J. H., \& Singh, H. (1998). The relational view: cooperative strategy and sources of interorganizational competitive advantage. Academy of Management Review, 23(4), 660-679.

Farrell, J., \& Saloner, G. (1985). Standardization, compatibility, and innovation. RAND Journal of Economics, 16(1), 70-83.

Gimeno, J. (2005). Competition within and between networks: the contingent effect of competitive embeddedness on alliance formation. Academy of Management Journal, 47(6), 820-842.

Gimeno, J., \& Woo, C. Y. (1996). Hypercompetition in a multimarket environment: the role of strategic similarity and multimarket contact in competitive de-escalation. Organization Science, 7(3), 322-341.

Gomes-Casseres, B. (1994). Group versus group: how alliance networks compete; organizations are gaining a competitive edge by moving beyond conventional two-company alliances. Harvard Business Review, 72(4), 62-74. 
Gomes-Casseres, B. (1996). The alliance revolution: the new shape of business rivalry. Cambridge: Harvard University Press.

Grandori, A., \& Soda, G. (1995). Inter-firm networks: antecedents, mechanisms and forms. Organization Studies, 16(2), 183-214.

Granovetter, M. (1985). Economic action and social structure: the problem of embeddedness. American Journal of Sociology, 91(3), 481-510.

Gulati, R. (1995). Does familiarity breed trust? The implications of repeated ties for contractual choice in alliances. Academy of Management Journal, 38(1), 85-112.

Gulati, R., \& Gargiulo, M. (1999). Where do interorganizational networks come from? American Journal of Sociology, 104(5), 1439-1493.

Hanlon, P. (1999). Global airlines: competition in a transnational industry (2nd ed.). Oxford: Butterworth Heinemann.

Hannan, M. T., \& Freeman, J. (1989). Organizational ecology. Cambridge: Harvard University Press.

Heckman, J. J. (1979). Sample selection bias as a specification error. Econometrica, 47(1), 153-161.

Jarillo, J. C. (1988). On strategic networks. Strategic Management Journal, 9(1), 31-41.

Jones, C., Hesterly, W. S., Fladmoe-Lindquist, K., \& Borgatti, S. P. (1998). Professional service constellations: how strategies and capabilities influence collaborative stability and change. Organization Science, 9(1), 396-410.

Joshi, M. P., Kashlak, R. J., \& Sherman, H. D. (1998). How alliances are reshaping telecommunications. Long Range Planning, 31(4), 542-548.

Lavie, D. (2007). Alliance portfolios and firm performance: a study of value creation and appropriation in the U.S. software industry. Strategic Management Journal, 28(12), 1187-1212.

Lavie, D., Lechner, C., \& Singh, H. (2007). The performance implications of timing of entry and involvement in multipartner alliances. Academy of Management Journal, 50(3), 578-604.

Lazzarini, S. G. (2007). The impact of membership in competing firm constellations: evidence on the operational performance of global airlines. Strategic Management Journal, 28(4), 345-367.

Lazzarini, S. G., \& Joaquim, T. A. Z. (2004). Formação de constelações de alianças: dados da indústria aérea global. Revista de Administração de Empresas, 44(2), 11-25.

Levinthal, D. A. (1997). Adaptation on rugged landscapes. Management Science, 43(7), 934-950.

Lorenzoni, G., \& Ornati, O. A. (1988). Constellations of firms and new ventures. Journal of Business Venturing, 3(1), 41-57.

Nault, B. R., \& Tyagi, R. K. (2001). Implementable mechanisms to coordinate horizontal alliances. Management Science, 47(6), 787-799.

Nohria, N., \& Garcia-Pont, C. (1991). Global strategic linkages and industry structure. Strategic Management Journal, 12(Special Issue), 105-124.

Pisano, G. P. (1989). Using equity participation to support exchange: evidence from the biotechnology industry. Journal of Law, Economics, and Organization, 5, 108-126. 
Poppo, L., \& Zenger, T. R. (2002). Do formal contracts and relational governance function as substitutes or complements? Strategic Management Journal, 23(8), 707-726.

Rowley, T. J., Baum, J. A., Shipilov, A. V., Greve, H. R., \& Rao, H. (2004). Competing in groups. Managerial and Decision Economics, 25(6-7), 453-471.

Sakakibara, M. (2002). Formation of R\&D consortia: industry and company effects. Strategic Management Journal, 23(11), 1033-1050.

Thompson, J. D. (1967). Organizations in action: social science bases of administrative theory. New York: McGraw-Hill.

Uzzi, B. (1996). The sources and consequences of embeddedness for the economic performance of organizations: the network effect. American Sociological Review, 61(4), 674-698.

Vanhaverbeke, W., \& Noorderhaven, N. G. (2001). Competition between alliance blocks: the case of the RISC microprocessor technology. Organization Studies, 22(1), 1-30.

Wasserman, S., \& Faust, K. (1994). Social network analysis. Cambridge: Cambridge University Press.

Whitaker, R. (1996). Emerging mega-alliances. Airline Business, 12(9), 31.

Williamson, O. E. (1991). Comparative economic organization: the analysis of discrete structural alternatives. Administrative Science Quarterly, 36(2), 269-296. 
Figure 1: Hypothesized Relationships

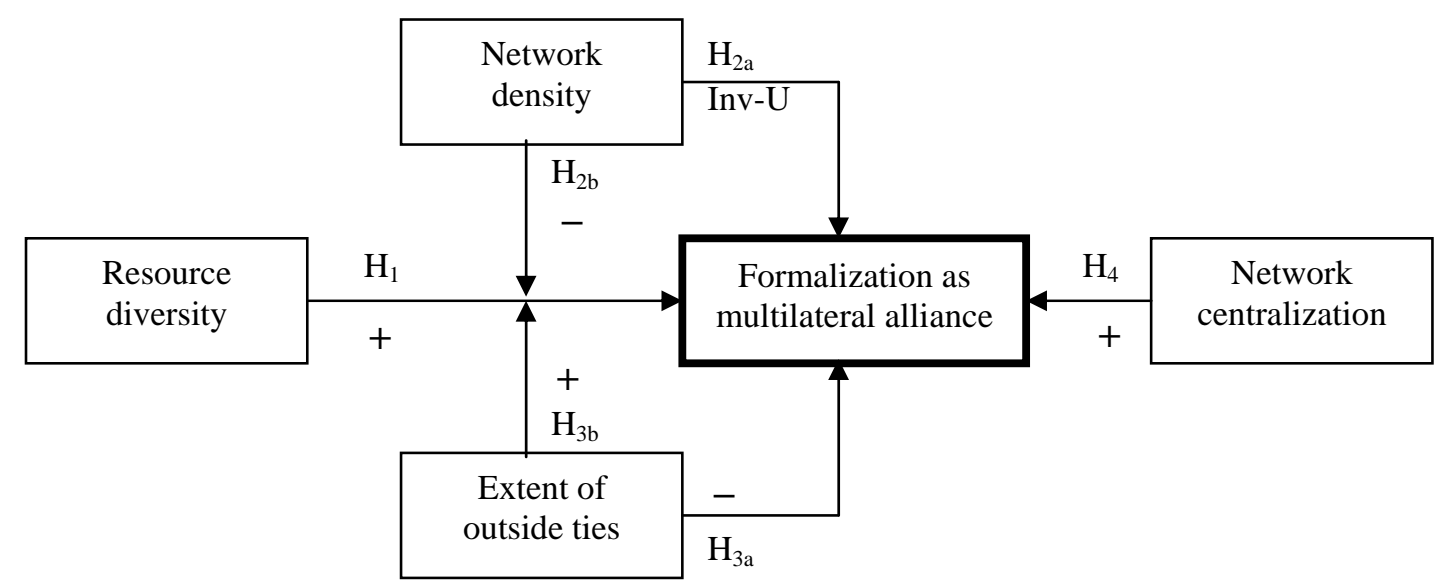


Table 1: Airline carriers included in the sample

\begin{tabular}{|c|c|c|c|c|c|}
\hline Carrier name (abbreviation) & Traffic* & Country & Carrier name (abbreviation) & Traffic* & Country \\
\hline Aer Lingus (LIN) & 8.889 & Ireland & Japan Air System (JAS) & 15.472 & Japan \\
\hline Aeroflot (AFL) & 16.557 & Russia & Japan Airlines (JA) & 88.999 & Japan \\
\hline Aerolineas Argentinas (ARG) & 11.111 & Argentina & KLM Royal Dutch Airl. (KLM) & 60.331 & Netherlands \\
\hline Aeromexico (AMX) & 14.390 & Mexico & Korean Air (KOR) & 40.467 & South Korea \\
\hline Air Algerie (ALG) & 3.051 & Algeria & LanChile (LCH) & 9.931 & Chile \\
\hline Air Canada (AC) & 44.806 & Canada & Lauda Air (LAÚ) & 4.562 & Austria \\
\hline Air China (CHI) & 18.116 & China & Lloyd Aero Boliviano (LAB) & 1.701 & Bolivia \\
\hline Air France (AFR) & 91.801 & France & LOT Polish Airlines (LOT) & 4.757 & Poland \\
\hline Air-India (IND) & 12.006 & India & Lufthansa (LFH) & 94.170 & Germany \\
\hline Air Liberte (LIB) & 4.707 & France & Malaysia Airlines (MA) & 37.947 & Malaysia \\
\hline Air New Zealand (ANZ) & 22.232 & New Zealand & Malev Hungarian Airlines (MAL) & 3.168 & Hungary \\
\hline Alaska Airlines (ALA) & 19.273 & United States & Mexicana de Aviacion (MEX) & 13.498 & Mexico \\
\hline Alitalia (ALI) & 40.618 & Italy & Northwest Airlines (NW) & 127.324 & United States \\
\hline All Nippon Airways (ANA) & 58.042 & Japan & Olympic Airways (OLY) & 8.860 & Greece \\
\hline America West Airlines (AW) & 30.742 & United States & Qantas Airways (QUA) & 63.495 & Australia \\
\hline American Airlines (AA) & 187.542 & United States & Royal Air Maroc (RAM) & 7.185 & Morocco \\
\hline Ansett Australia (ANS) & 17.110 & Australia & Royal Jordanian Airlines (RAJ) & 4.207 & Jordan \\
\hline AOM French Airlines (AOM) & 9.248 & France & Sabena (SAB) & 19.379 & Belgium \\
\hline Austrian Airlines (AUS) & 8.799 & Austria & Scandinavian Airlines (SAS) & 22.647 & Sweden \\
\hline Balkan Bulgarian (BAL) & 0.808 & Bulgaria & Saudi Arabian Airlines (SAU) & 20.229 & Saudi Arabia \\
\hline British Airways (BA) & 118.890 & United Kingdom & Singapore Airlines (SIN) & 70.795 & Singapore \\
\hline British Midland (BMI) & 3.837 & United Kingdom & South African Airways (SAA) & 19.321 & South Africa \\
\hline Canadian Airlines Intern. (CAI) & 23.395 & Canada & Sri Lankan Airlines (SLA) & 6.860 & Sri Lanka \\
\hline Cathay Pacific (CP) & 47.097 & Hong Kong & Swissair (SWR) & 34.246 & Switzerland \\
\hline Continental Airlines (CO) & 96.949 & United States & Syrian Arab Airlines (SYR) & 1.422 & Syria \\
\hline Croatia Airlines (CRO) & 0.644 & Croatia & TAP Air Portugal (TAP) & 10.385 & Portugal \\
\hline Crossair (CRS) & 2.073 & Switzerland & TAROM (TAR) & 2.075 & Romania \\
\hline CSA Czech Airlines (CSA) & 3.294 & Czech Republic & Thai Airways International (TAI) & 42.236 & Thailand \\
\hline Cyprus Airways (CYP) & 2.785 & Cyprus & Trans World Airlines (TWA) & 43.798 & United States \\
\hline Delta Air Lines (DL) & 173.411 & United States & Tunisair (TUN) & 2.694 & Tunisia \\
\hline Egyptair (EGY) & 9.086 & Egypt & Turkish Airlines THY (THY) & 16.492 & Turkey \\
\hline $\mathrm{El} \mathrm{Al} \mathrm{(EL)}$ & 14.125 & Israel & Ukraine Intern. Airlines (UKR) & 0.401 & Ukraine \\
\hline Emirates (EMI) & 19.413 & Un. Arab Emirates & United Airlines (UA) & 204.187 & United States \\
\hline Finnair (FIN) & 7.460 & Finland & US Airways (USAir) (USA) & 75.380 & United States \\
\hline GB Airways (GB) & 1.971 & United Kingdom & Varig (VRG) & 26.286 & Brazil \\
\hline Gulf Air (GUL) & 12.739 & Bahrain & VASP Brazilian Airlines (VSP) & 4.918 & Brazil \\
\hline Iberia Airlines (IBR) & 40.015 & Spain & Virgin Atlantic Airways (VIR) & 29.471 & United Kingdom \\
\hline Iran Air (IRA) & 6.229 & Iran & & & \\
\hline
\end{tabular}


Table 2: Factors Influencing the Extent to Which Firms in Network Samples are Observed in the Same Multilateral Alliance: Two-stage Heckman estimates ${ }^{\mathrm{a}}$

\begin{tabular}{|c|c|c|c|}
\hline & Model 1 & Model 2 & Model 3 \\
\hline \multicolumn{4}{|l|}{ Resource profile } \\
\hline Hub diversity & & $\begin{array}{l}0.008^{* *} \\
(0.001)\end{array}$ & $\begin{array}{l}0.008 * * \\
(0.001)\end{array}$ \\
\hline Capacity diversity & & $\begin{array}{l}0.001 * \\
(0.000)\end{array}$ & $\begin{array}{l}0.001 * \\
(0.000)\end{array}$ \\
\hline \multicolumn{4}{|l|}{ Network structure } \\
\hline Density & & $\begin{array}{l}0.290 * * \\
(0.039)\end{array}$ & $\begin{array}{l}0.289 * * \\
(0.039)\end{array}$ \\
\hline Density $^{2}$ & & $\begin{array}{l}-0.714 * * \\
(0.181)\end{array}$ & $\begin{array}{l}-0.845 * * \\
(0.189)\end{array}$ \\
\hline Centralization & & $\begin{array}{c}0.044 \\
(0.015)\end{array}$ & $\begin{array}{c}0.044 \text { ** } \\
(0.015)\end{array}$ \\
\hline Outside ties & & $\begin{array}{r}-0.099 \\
(0.125)\end{array}$ & $\begin{array}{l}-0.111 \\
(0.124)\end{array}$ \\
\hline \multicolumn{4}{|l|}{ Interactions } \\
\hline Density× Hub diversity & & & $\begin{array}{l}-0.043 * * \\
(0.013)\end{array}$ \\
\hline Density $\times$ Capacity diversity & & & $\begin{array}{r}0.002 \\
(0.002)\end{array}$ \\
\hline Outside× Hub diversity & & & $\begin{array}{r}0.085 * \\
(0.047)\end{array}$ \\
\hline Outside×Capacity diversity & & & $\begin{array}{r}0.003 \\
(0.009)\end{array}$ \\
\hline \multicolumn{4}{|l|}{ Controls $^{\mathrm{b}}$} \\
\hline Multimarket contact & $\begin{array}{l}0.004 * * \\
(0.001)\end{array}$ & $\begin{array}{l}0.005 * * \\
(0.001)\end{array}$ & $\begin{array}{l}0.005 * * \\
(0.001)\end{array}$ \\
\hline Average traffic & $\begin{array}{l}0.001 * * \\
(0.000)\end{array}$ & $\begin{array}{r}0.000 \\
(0.000)\end{array}$ & $\begin{array}{r}0.000 \\
(0.000)\end{array}$ \\
\hline Cargo diversity & $\begin{array}{r}-0.166 \\
(0.579)\end{array}$ & $\begin{array}{r}-0.573 \\
(0.577)\end{array}$ & $\begin{array}{r}-0.541 \\
(0.574)\end{array}$ \\
\hline Average routes & $\begin{array}{r}0.087 \\
(0.053)\end{array}$ & $\begin{array}{c}0.142 \\
(0.051)\end{array}$ & $\begin{array}{l}0.144 \text { ** } \\
(0.051)\end{array}$ \\
\hline Intercept & $\begin{array}{l}-0.153 * \\
(0.069)\end{array}$ & $\begin{array}{l}-0.217 * * \\
(0.075)\end{array}$ & $\begin{array}{l}-0.208 \text { ** } \\
(0.074)\end{array}$ \\
\hline Inverse Mills ratio & $\begin{array}{l}0.287 * * \\
(0.075)\end{array}$ & $\begin{array}{l}0.231 * * \\
(0.071)\end{array}$ & $\begin{array}{l}0.214 \text { ** } \\
(0.068)\end{array}$ \\
\hline F statistic & $8.73 * *$ & $10.73 * *$ & $9.94 * *$ \\
\hline
\end{tabular}

